\title{
Close spacing of AUG initiation codons confers dicistronic character on a eukaryotic mRNA
}

\author{
DAIKI MATSUDA ${ }^{1}$ and THEO W. DREHER ${ }^{1,2}$ \\ ${ }^{1}$ Department of Microbiology, Oregon State University, Corvallis, Oregon 97331-3804, USA \\ ${ }^{2}$ Center for Genome Research and Biocomputing, Oregon State University, Corvallis, Oregon 97331-3804, USA
}

\begin{abstract}
TYMV RNA supports the translation of two proteins, p69 and p206, from AUG initiation codons 7 nucleotides apart. We have studied the translation of this overlapping dicistronic mRNA with luciferase reporter RNAs electroporated into cowpea protoplasts and in toe-printing studies that map ribosomes stalled during initiation in wheat germ extracts. Agreement between these two assays indicates that the observed effects reflect ribosome initiation events. The robust expression from the downstream $\mathrm{AUG}^{206}$ codon was dependent on its closeness to the upstream $\mathrm{AUG}^{69}$ codon. Stepwise separation of these codons resulted in a gradual increase in upstream initiation and decrease in downstream initiation, and expression was converted from dicistronic to monocistronic. Selection by ribosomes for initiation between the nearby AUG codons was responsive to the sequence contexts that govern leaky scanning, but the normally strong position effect favoring upstream initiation was greatly diminished. Similar dicistronic expression was supported for RNAs with altered initiation sequences and for RNAs devoid of flanking viral sequences. Closely spaced AUG codons may thus represent an under-recognized strategy for bicistronic expression from eukaryotic mRNAs. The initiation behavior observed in these studies suggests that $5^{\prime}-3^{\prime}$ ribosome scanning involves backward excursions averaging about 15 nucleotides.
\end{abstract}

Keywords: leaky scanning; luciferase reporter; ribosome scanning, mechanism; translation initiation, initiation coupling; Turnip yellow mosaic virus

\section{INTRODUCTION}

A fundamental difference between the designs of prokaryotic and eukaryotic messenger RNAs is that the former typically serve as multicistronic expression units encoding proteins from an operon, whereas the latter are typically monocistronic (Kozak 1999). This design dichotomy is the result of very different ways in which ribosomes are recruited to mRNAs in the two systems. In bacteria, local ribosome binding sites that are positioned just upstream of an initiation codon function independently to recruit a ribosome and to direct it to the appropriate start site. Multiple such ribosome entry sites can exist on an mRNA, and these can even function on a circular RNA, underscoring the unimportance of position relative to the $5^{\prime}$-end (Kozak 1999).

Reprint requests to: Theo W. Dreher, Department of Microbiology, 220 Nash Hall, Oregon State University, Corvallis, OR 97331-3804, USA; e-mail: theo.dreher@oregonstate.edu; fax: (541) 737-0496.

Article published online ahead of print. Article and publication date are at http://www.rnajournal.org/cgi/doi/10.1261/rna.67906.
In the typical eukaryotic mRNA, a network of interactions dependent on the $5^{\prime}{ }^{-\mathrm{m} 7} \mathrm{GpppN}$ cap recruits ribosomes to the $5^{\prime}$-end (Pestova et al. 2001). Scanning toward the $3^{\prime}$ end follows, with the first encountered AUG triplet usually serving as the sole site for productive initiation of protein synthesis. Eukaryotic translational expression is thus characterized by 5 '-polarity (sometimes called the "position effect") (Kozak 2002) and expression of a single polypeptide per mRNA. Layered onto this view of eukaryotic mRNA translation are a number of mechanisms that are known to modify ribosome behavior and potentially relieve the restrictions to monocistronic expression, discussed in depth by Kozak (2002): (a) leaky scanning, whereby the $5^{\prime}$-most AUG lies in a suboptimal sequence context (determined principally by nucleotides -6 to +5 relative to the A of an AUG) and is passed over by a proportion of scanning ribosomes, which can then initiate at an alternative AUG downstream; (b) leaky scanning in which certain non-AUG codons that can serve as weak initiation codons are passed over by some ribosomes; (c) reinitiation by ribosomes that have resumed scanning after translating an 
initial short open reading frame (ORF); (d) cap-independent initiation through an internal ribosome entry site (IRES) (Sachs et al. 1997; Jackson 2005).

Although there have been many instances of these phenomena described, they nevertheless fall outside the typical paradigm describing eukaryotic translation, in which mRNAs are considered to be essentially monocistronic. Recent genome-wide computational studies, however, suggest that alternative ribosomal behaviors that can result in additional translation initiation sites are not in fact rare. Such sites can be either upstream of or downstream from the primary initiation site. Upstream AUG triplets were found in $40 \%-50 \%$ of full-length expressed mammalian sequences (Yamashita et al. 2003; Iacono et al. 2005), and at least $20 \%-30 \%$ of mammalian and yeast mRNAs were estimated to have conserved upstream AUGs (Churbanov et al. 2005). Many of the upstream AUGs initiate short ORFs embedded in the 5'-UTR, and, although they are mostly thought to regulate the expression of the main ORF (Kozak 2002; Churbanov et al. 2005; Hinnebusch 2005; Iacono et al. 2005), it is possible that some encode short biologically active peptides (Oyama et al. 2004). Considering potential alternative initiation downstream from the primary initiation site, the abundance of mRNAs whose $5^{\prime}$-most AUG triplets are in suboptimal contexts (absence of a purine at -3 and/or G at +4 ) has suggested that as many as half of human mRNAs could express more than one polypeptide through a leaky scanning mechanism; this would seem especially likely for the $12.5 \%$ of mRNAs lacking both purine at -3 and $\mathrm{G}$ at +4 (Smith et al. 2005). Many of these hypothetical cases would be expected to involve the production of small peptides that have routinely been excluded from sequence annotations and protein preparations and thus have received scant experimental attention.

The alternative ribosome behaviors that can expand the translation repertoire of an mRNA typically occur with low efficiency, such that the expression from secondary initiation codons is likely to be limited (Kozak 2002). This may be appropriate for the expression of biologically active second polypeptides that have potent effects at lower concentrations, such as the 14-residue osteogenic growth peptide translated by leaky scanning from mammalian histone H4 mRNA (Bab et al. 1999). However, the robust expression of two polypeptides from extensively overlapping ORFs encoded by the genomic RNA of Turnip yellow mosaic virus (TYMV) indicates that eukaryotic mRNAs can be efficiently bicistronic. We report here our investigations showing that the relatively strong and balanced expression of these ORFs is a function of the close spacing ( $7 \mathrm{nt}$ apart) of their initiation codons. This proximity modifies normal leaky scanning, such that initiation decisions involving the two AUGs are no longer strictly sequential with 5 '-polarity, but competitive. Our results are best explained by interpreting ribosome scanning as involving small-amplitude forward and backward oscillations ("fluttering") with a net $5^{\prime}-3^{\prime}$ movement.

\section{RESULTS}

\section{Separation of the two closely spaced initiation codons of TYMV RNA produces an RNA that is effectively monocistronic}

TYMV genomic RNA is a positive-sense mRNA that is translated efficiently to produce two proteins, the p69 movement/RNAi suppressor protein and p206, the replication polyprotein, from extensively overlapping ORFs (Dreher 2004; Fig. 1A). The 7-nt spacing between the $\mathrm{AUG}^{69}$ and $\mathrm{AUG}^{206}$ initiation codons (Fig. 1B) is conserved among tymoviruses, though the sequence contexts vary. Since none of the tymoviral $\mathrm{AUG}^{69}$ codons possess optimal contexts, a leaky scanning mechanism is plausible in explaining ribosome access to $\mathrm{AUG}^{206}$. However, our previous observation that mutation of $\mathrm{AUG}^{206}$ to ACG increased translation from the upstream $\mathrm{AUG}^{69}$ (Matsuda et al. 2004) is inconsistent with the normal $5^{\prime}$-polarity of leaky scanning, suggesting that the translation of TYMV RNA might employ a novel variant of conventional leaky scanning. Additional uncertainty concerning the translation of TYMV RNA was introduced recently by the proposal (Barends et al. 2003) that ribosomes initiating at $\mathrm{AUG}^{206}$ do so by a mechanism more related to initiation at the Cricket paralysis virus IGR IRES (Jan 2005) than via cap-dependent scanning through the $5^{\prime}$-UTR.

Expression from the downstream $\mathrm{AUG}^{206}$ initiation codon of TYMV RNA is about threefold lower than from AUG $^{69}$ (Fig. 1D). We have observed this in experiments measuring protein expression in cowpea mesophyll protoplasts from paired reporter constructs, 69L-TYg and 206LTYg encoding firefly luciferase (LUC) (Fig. 1C; Matsuda et al. 2004). These RNA constructs contain the complete $5^{\prime}$ - and 3'-UTRs from TYMV genomic RNA. In addition, to preserve the native ribosome behavior in the translation initiation region, the reporter RNAs include $129 \mathrm{nt}$ of the TYMV coding region downstream from $\mathrm{AUG}^{69}$, thereby encoding N-terminal fusion derivatives of LUC (abbreviated $69 \mathrm{~L}$ and 206L). The 69L-TYg and 206L-TYg RNAs differ by only the absence or presence of a single nucleotide at the junction between TYMV and LUC sequences that places ORF69 or ORF206 in-frame with the LUC ORF. We have previously shown that the physical stabilities of these two RNAs are similar in vivo and that the $69 \mathrm{~L}$ and $206 \mathrm{~L}$ fusion forms of LUC have similar light-yielding specific activity, permitting direct comparisons (Matsuda et al. 2004). In the studies described here, we report initial rates of expression from the early quasi-linear phase of LUC production.

The 3:1 69L to 206L expression ratio represents relatively efficient dicistronic expression. To explore whether expression from the downstream $\mathrm{AUG}^{206}$ was robust because of its 
A

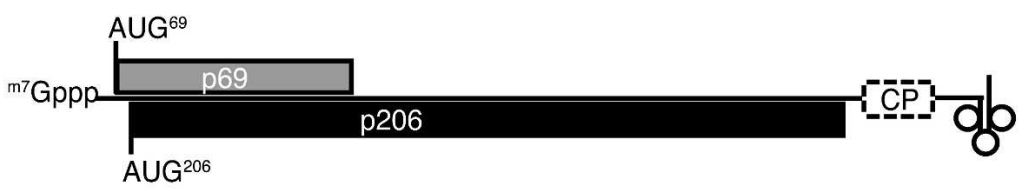

B

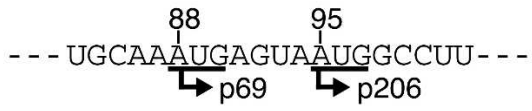

C
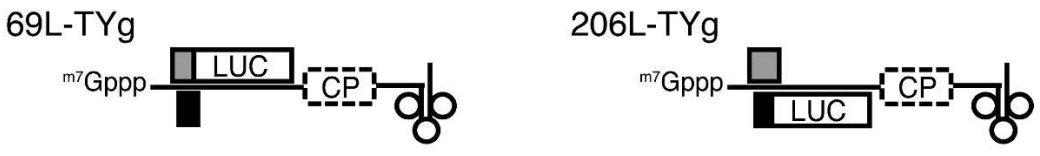

D

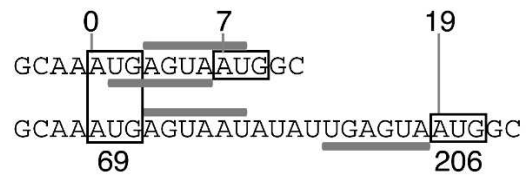

$69 \mathrm{~L}$ and $206 \mathrm{~L}$ expression in cowpea protoplasts

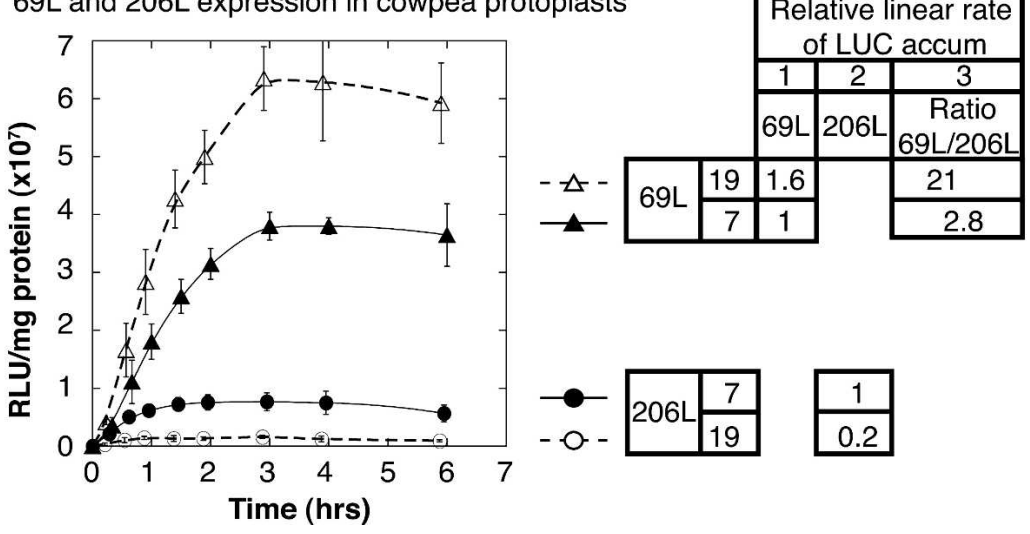

FIGURE 1. Expression from the two closely spaced AUGs of TYMV RNA varies with increased spacing. $(A)$ Diagram of the 6.3-kb TYMV genomic RNA. The p69 (gray box) and p206 (black box) coding regions are expressed by initiation from $\mathrm{AUG}^{69}$ and $\mathrm{AUG}^{206}$, respectively. The coat protein coding region (CP, open-dashed box) is silent in genomic RNA, being expressed from a subgenomic RNA (not shown). TYMV RNA is $5^{\prime}$-capped $\left({ }^{m 7} \mathrm{GpppN}\right)$ and terminates with the $3^{\prime}$-tRNA-like structure (cloverleaf). (B) The sequence surrounding the two initiation AUGs at nucleotides 88 and 95. (C) Paired LUC-expressing reporter RNA constructs used to investigate translation from the two AUGs. Each RNA contains $217 \mathrm{nt}$ of sequence from the $5^{\prime}$-end (including $130 \mathrm{nt}$ of coding sequence) and $684 \mathrm{nt}$ from the $3^{\prime}$-end (the entire $3^{\prime}$-UTR including the silenced CP ORF) of TYMV genomic RNA. These regions flank the firefly LUC coding region in front of a 19-nt plasmid-derived bridging sequence. The RNAs 69L-TYg and 206L-TYg encode the LUC fusion proteins 69L or 206L, which have an $\mathrm{N}$-terminal fusion of 43 and 41 amino acids from the N-terminal portions of p69 and p206, respectively. (D) Expression profiles of 69L and 206L in cowpea protoplasts after electroporation of RNAs with 7- or 19-nt spacing between $\mathrm{AUG}^{69}$ and $\mathrm{AUG}^{206}$. The linear rates of accumulation of reporter protein (in RLU/h) determined from the time-courses are tabulated at right. All data in this and subsequent figures were derived by pooling two independent electroporation experiments with duplicate transcripts per experiment (four data points); error bars represent the standard deviation.

close spacing to $\mathrm{AUG}^{69}$, we introduced a 12-nt spacer between the two initiation codons while retaining the sequence context surrounding each AUG. This resulted in a 1.6-fold increase in 69L expression along with a fivefold decrease in 206L expression (Fig. 1D). With a ratio of expression from AUG $^{69}$ relative to $\mathrm{AUG}^{206}$ of 21 , separation of the two AUGs has produced mRNAs that are effectively monocistronic. This suggests that conventional leaky scanning is only capable of minimal expression from $\mathrm{AUG}^{206}$ and that some form of expression coupling exists between the closely spaced $\mathrm{AUG}^{69}$ and $\mathrm{AUG}^{206}$.

\section{Gradual decoupling of $A \cup G^{69}$ from $\mathrm{AUG}^{206}$ with distance}

We have previously reported that knockout of the downstream $\mathrm{AUG}^{206}$ by mutation to ACG resulted in a 2.5 fold higher expression rate from the upstream AUG ${ }^{69}$ (Matsuda et al. 2004). This mutation did not alter the coding of ORF69 and did not alter the predicted secondary structure of the RNA. Similar observations were made with AUG $^{206}$ knockout to AAG or AUU (data not shown). These results indicate that the increased expression from $\mathrm{AUG}^{69}$ was a direct response to the removal of the downstream initiation site. Atypical of normal, polar leaky scanning, the two closely spaced initiation sites appear to be coupled and in competition with each other.

To explore more closely the dependence of coupling on proximity, we compared 69L and 206L expression from a set of paired constructs in which the initiation sites were progressively separated by multiples of three additional nucleotides. The distance between the A residues of the two AUGs thus ranged from the wild-type $7 \mathrm{nt}$ to a maximum of $19 \mathrm{nt}$ (Fig. 2A). The inserted sequences were carefully chosen to retain the original initiation contexts $(-4$ to +7$)$ and to avoid stable secondary structure that may influence the behavior of ribosomes. The effect on 69L expression resulting from knockout of $\mathrm{AUG}^{206}$ was assayed as a measure of the coupling between the two initiation sites (Fig. 2B). The knockout-dependent increase in expression from $\mathrm{AUG}^{69}$ gradually decreased with greater spacing, and no longer occurred with a spacing of 19 , and perhaps even 16, nucleotides (Fig. 2B). 
A
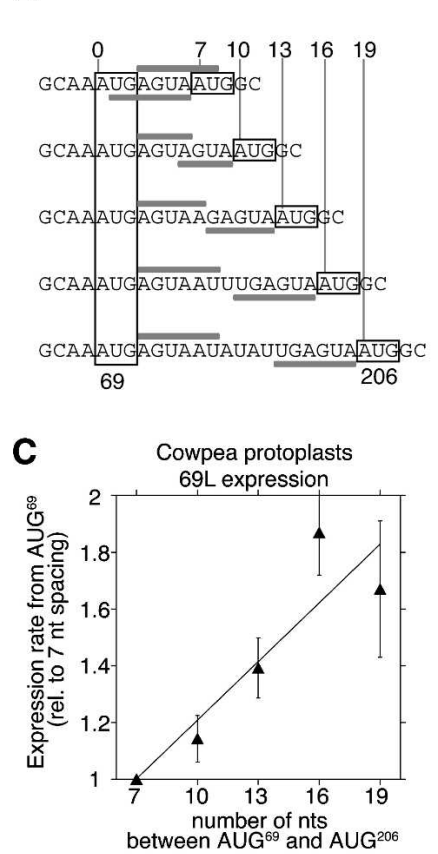

$\mathbf{E}$

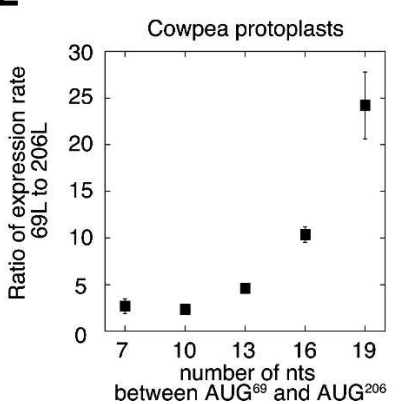

B

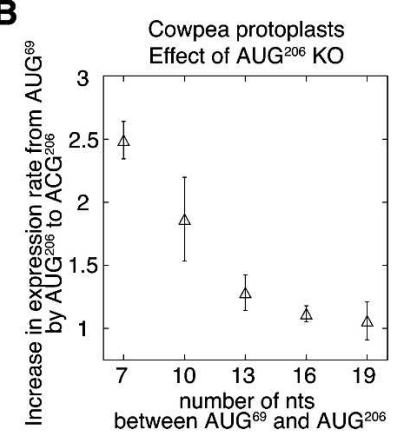

D

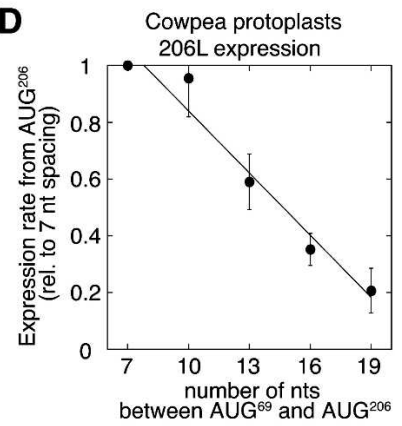

$\mathbf{F}$

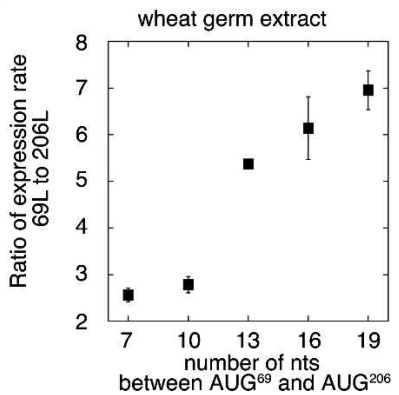

FIGURE 2. Effect of stepwise separation of the two AUGs. (A) Sequences surrounding the two initiation codons (boxed) in paired derivatives of 69L-TYg and 206L-TYg RNAs are shown. Insertions between $\mathrm{AUG}^{69}$ and $\mathrm{AUG}^{206}$ increase the spacing in triplets from $7 \mathrm{nt}$ (in wild type) to $19 \mathrm{nt}$. The sequence contexts between $\mathrm{AUG}^{69}$ and $\mathrm{AUG}^{206}$ that are preserved in each construct are highlighted with lines above or below the sequences. (B-E) Effects of increased spacer length, as assayed in cowpea protoplasts, on $(B)$ increased $69 \mathrm{~L}$ expression caused by mutation (knockout) of $\mathrm{AUG}^{206},(C) 69 \mathrm{~L}$ expression and $(D)$ 206L expression, and $(E)$ the expression ratio of 69L to 206L. (F) Effect of increased spacer length on the expression ratio of $69 \mathrm{~L}$ to $206 \mathrm{~L}$, assayed in a wheat germ in vitro translation system.

Similar gradual changes were observed in the expression rates from the two initiation sites when the spacing between them was increased. The rate of expression from $\mathrm{AUG}^{69}$ increased to a maximum of about twice wild type (at 16 or $19 \mathrm{nt}$ spacing) (Fig. 2C), while that from $\mathrm{AUG}^{206}$ fell to a minimum of $20 \%$ relative to wild type (at $19 \mathrm{nt}$ spacing) (Fig. 2D). There was consequently also a gradual increase in the 69L:206L expression ratio and in the transition to a functionally monocistronic mRNA (Fig. 2E). The recipro-

cal effect on LUC reporter expression from each AUG in response to physical separation was also reproduced in a wheat germ in vitro translation system (Fig. 2F).

The gradual changes observed for expression from the two AUGs and in the response to AUG ${ }^{206}$ knockout indicate that the coupling phenomenon does not rely on a specific spacing of AUGs. If that were the case, sudden loss of coupling and 206L expression would have been expected upon separation beyond some tolerated spacing. We interpret the results of Figure 2 as emphasizing the competitive relationship between initiation at the two AUGs and as indicating that initiation choices by ribosomes are probabilistic rather than all-or-nothing.

\section{Ribosomes reaching both $\mathrm{AUG}^{69}$ and $\mathrm{AUG}^{206}$ load onto the RNA at the $5^{\prime}$-cap}

Before further investigating the features that govern the selection by ribosomes between these two initiation sites, we wished to confirm that both sites are reached by conventional ribosome trafficking. It was recently proposed that, while ribosomes scanning from the $5^{\prime}$-cap initiate at $\mathrm{AUG}^{69}$, initiation at the downstream $\mathrm{AUG}^{206}$ is a special case of cap-independent translation that intimately involves the 3'-tRNA-like structure, which perhaps even loads into a decoding site of the ribosome (Barends et al. 2003). Our previous studies do not confirm this proposal (Matsuda et al. 2004). We observed that expression from both $\mathrm{AUG}^{69}$ and $\mathrm{AUG}^{206}$ is highly dependent on a cap, and that the $3^{\prime}$-UTR containing the tRNA-like structure is a generic enhancer of translation; no special relationship with initiation from $\mathrm{AUG}^{206}$ was evident. Our experiments were conducted in cells (cowpea protoplasts), whereas the scheme of Barends et al. (2003) was based entirely on experiments conducted in vitro.

To verify ribosomal loading at the $5^{\prime}$-end of the RNA, we introduced a 13-bp stem-loop structure (calculated free energy of $-26.5 \mathrm{kcal} / \mathrm{mol}$ ) expected to inhibit ribosome loading (Kozak 1989; Niepel and Gallie 1999) at the 5'termini of the 69L-TYg and 206L-TYg RNAs (Fig. 3A). Translation in cowpea protoplasts from both $\mathrm{AUG}^{69}$ and AUG $^{206}$ was suppressed to background levels (Fig. 3B). These results show that ribosomes initiating at both AUGs are loaded at the $5^{\prime}$-terminus in a standard cap-dependent manner, consistent with conventional initiation involving scanning through the $5^{\prime}$-UTR.

\section{Selection between the two initiation sites is governed by the sequence context of each AUG}

The sequence context (especially nucleotides at positions -3 and +4 with respect to the A of an AUG triplet) is known to be an important factor in initiation site selection (Kozak 2002). We investigated the role sequence context plays in the competition between the $\mathrm{AUG}^{69}$ and $\mathrm{AUG}^{206}$ 
A

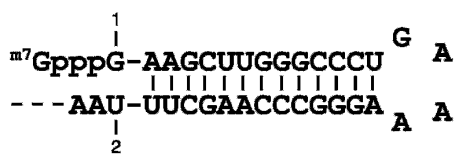

B

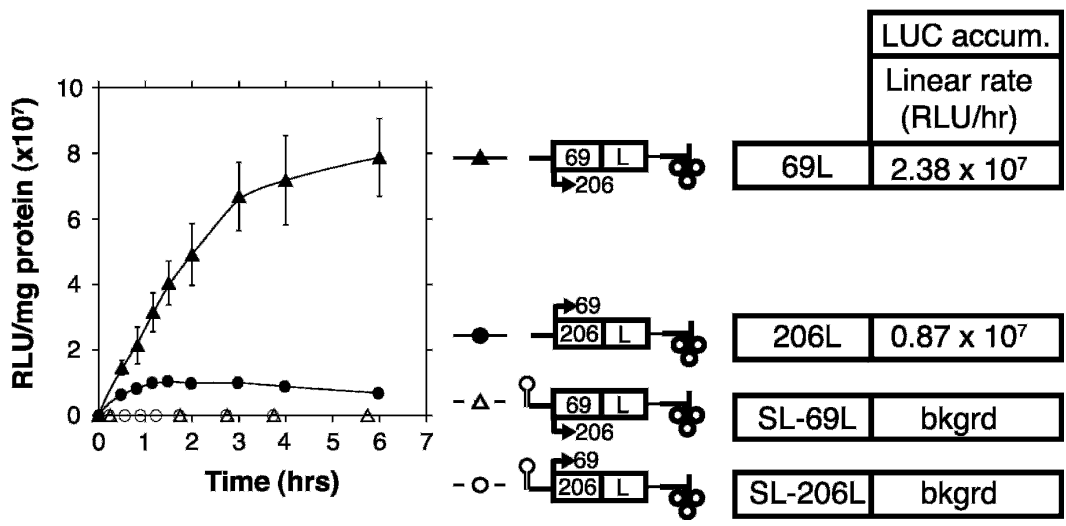

FIGURE 3. Ribosomes associate with the $5^{\prime}$-end to reach the two AUGs. (A) Diagram showing the sequence of the 13 -bp stem-loop $(-26.5 \mathrm{kcal})$ located adjacent to the $5^{\prime}$-cap and used to suppress the association of ribosomes with the $5^{\prime}$-end of the TYMV $5^{\prime}$-UTR. The stemloop was inserted between the first and second nucleotides of the TYMV $5^{\prime}$-UTR. (B) Expression profiles of $69 \mathrm{~L}$ and $206 \mathrm{~L}$ in cowpea protoplasts after electroporation of control 69L-TYg and 206L-TYg RNAs and derivatives with the 13-bp 5' stem-loop (SL).
Knockout of $\mathrm{AUG}^{206}$, which increased the $69 \mathrm{~L}$ expression rate $(2.5$-fold; Fig. $4 \mathrm{~B})$, reveals the coupled nature of expression from these two AUGs that is not expected of typical leaky scanning.

In the strong-weak context combination, knockout of $\mathrm{AUG}^{206}$ had negligible effect on expression from AUG $^{69}$ (Fig. 4B), while knockout of $\mathrm{AUG}^{69}$ increased the rate of expression from $\mathrm{AUG}^{206}$ 94-fold (Fig. 4B). With such skewed context strengths in favor of the upstream site, behavior is as expected of typical leaky scanning. The observed results are not inconsistent with competitive selection between the two initiation sites, however, since the background expression of 206L represents little opportunity for increased 69L expression upon $\mathrm{AUG}^{206}$ knockout.

In the weak-strong context combination, knockout of $\mathrm{AUG}^{206}$ increased the expression rate of $69 \mathrm{~L}$ by 9.5 -fold (Fig. 4B), much greater than the 2.5fold effect observed with the wild-type context. Coupling is clearly operative. Knockout of $\mathrm{AUG}^{69}$ increased expres-

initiation sites by converting the native contexts (weakmoderately strong) to strong-weak and weak-strong (referring to $A U G^{69}-A_{U G}{ }^{206}$, respectively) (Fig. 4A). Spacing between the initiation codons was kept at $7 \mathrm{nt}$.

The strong-weak context combination increased the rate of expression from $\mathrm{AUG}^{69}$ by 2.2 -fold, while expression from $\mathrm{AUG}^{206}$ fell to near background (Fig. 4A). This combination of contexts thus results in monocistronic expression. In contrast, the weak-strong context combination resulted in only $15 \%$ the normal rate of expression from $\mathrm{AUG}^{69}$, but 5.2 -fold increased expression from $\mathrm{AUG}^{206}$ (Fig. 4A). This RNA thus expresses 206L at a rate about 12 times higher than 69L. Context sequences thus are powerful factors in guiding ribosomes in their selection between $\mathrm{AUG}^{69}$ and $\mathrm{AUG}^{206}$. Altering contexts allows dominant initiation to be switched between the upstream and downstream sites.

Control of initiation by sequence context is the underlying principle of leaky scanning. However, conventional leaky scanning is a $5^{\prime}$-dependent sequential process with no coupling or mutual competition between two initiation sites as we have observed with the TYMV $5^{\prime}$ sequence. To determine whether coupling is retained after altering the sequence contexts, we assayed the response of expression from each initiation site upon knockout of the other AUG. As reported previously for the wild-type sequence (Matsuda et al. 2004), knockout of $\mathrm{AUG}^{69}$ increased the 206L expression rate (4.4-fold; Fig. 4B). sion of 206L only marginally (Fig. 4B), reflective of the low pre-existing expression from $\mathrm{AUG}^{69}$.

Taken together, these results show that relative translation from the closely spaced AUGs is governed by the relative strengths of their sequence contexts. Additionally, the coupled expression that enhances initiation at the nearby downstream AUG can occur with other sequence contexts and is not a special phenomenon restricted to the native TYMV sequence.

\section{Translational coupling originates at initiation (initiation coupling)}

Because the close spacing of $\mathrm{AUG}^{69}$ and $\mathrm{AUG}^{206}$ restricts interaction of the initiation region to a single ribosome at a time, we hypothesized that the coupled expression of $69 \mathrm{~L}$ and $206 \mathrm{~L}$ originates at translation initiation, rather than an event that follows initiation. We employed toe-printing analysis in wheat germ extracts to directly assay ribosome interaction with $\mathrm{AUG}^{69}$ and $\mathrm{AUG}^{206}$ in the initiation step. Cycloheximide is used to arrest ribosomes at the initiation codons, and those ribosomes are detected by reverse transcriptase-driven extension of a $5^{\prime}$-labeled oligomeric primer that is annealed to the downstream coding region (Ryabova and Hohn 2000; Sachs et al. 2002). The analysis directly assays the proportion of ribosomes stalled at each of the two AUGs. 
A

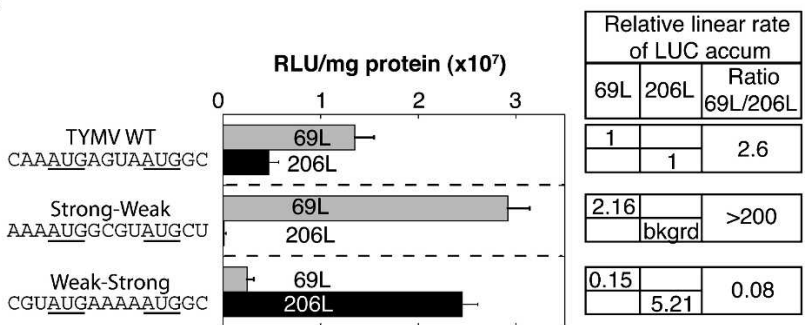

B

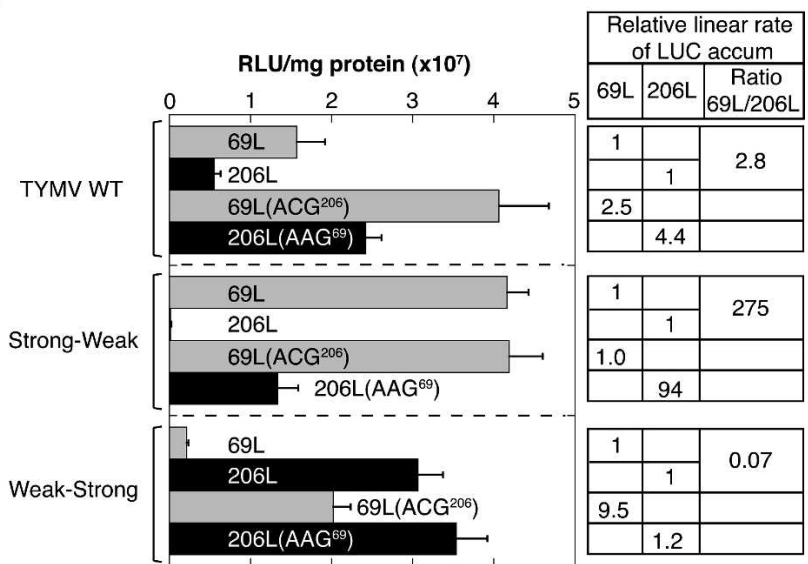

FIGURE 4. Changes in the initiation codon sequence contexts lead to altered ratios of $69 \mathrm{~L}$ to $206 \mathrm{~L}$, but translational coupling is retained. (A) Expression in cowpea protoplasts of 69L and 206 is shown for reporter mRNAs with wild-type or variant initiation cassette (nt 8599). Note that in dicot plants, AAAAUGGC appears to be the optimal context for translation initiation (Joshi et al. 1997; Lukaszewicz et al. 2000; Kawaguchi and Bailey-Serres 2005). (B) Expression in cowpea protoplasts of 69L and 206L is shown for reporter mRNAs with knockout mutations of $\mathrm{AUG}^{69}$ or $\mathrm{AUG}^{206}$ as indicated. The knockout mutations do not alter the encoded amino acid sequence. Loss of expression by both AUG mutations was previously confirmed in the wild-type context by in vitro translation of full-length TYMV RNA transcripts (Weiland and Dreher 1989).

Initially, the concentrations of input RNA transcripts, $\mathrm{Mg}^{2+}$, and $\mathrm{K}^{+}$in the wheat germ extract were adjusted to produce a similar 69L:206L expression ratio as found in cowpea protoplasts and to ensure that RNA was in the linear response range. Corresponding to the 2.6-2.8 ratio of 69L:206L expression rate seen in cowpea protoplasts (Fig. 4), a ratio of 2.4-2.7 was observed between ribosomes stalled at $\mathrm{AUG}^{69}$ relative to $\mathrm{AUG}^{206}$ when cycloheximide was added after a 30-min period of translation (Fig. 5A; lanes 1,2). Similar ribosome behavior was observed on fulllength in vitro transcribed TYMV RNA and on virion genomic RNA (Fig. 5A, lanes 3,4) as on the 69L-TYg and 206L-TYg reporter RNAs (lanes 1,2). This validates our use of the paired reporter constructs in studying ribosome behavior on TYMV RNA.

To preclude any influence of elongating ribosomes on initiation, further toe-printing experiments were conducted with cycloheximide present from the beginning of the incubation. This resulted in an altered ratio of ribosomes stalled at $\mathrm{AUG}^{69}$ relative to $\mathrm{AUG}^{206}$ (Fig. 5B), but, importantly, toe-prints were again similar on genomic transcript or virion RNAs and on the 69L-TYg and 206LTYg reporter RNAs (Fig. 5B, cf. lanes 3,4 and lanes 1,2).

A
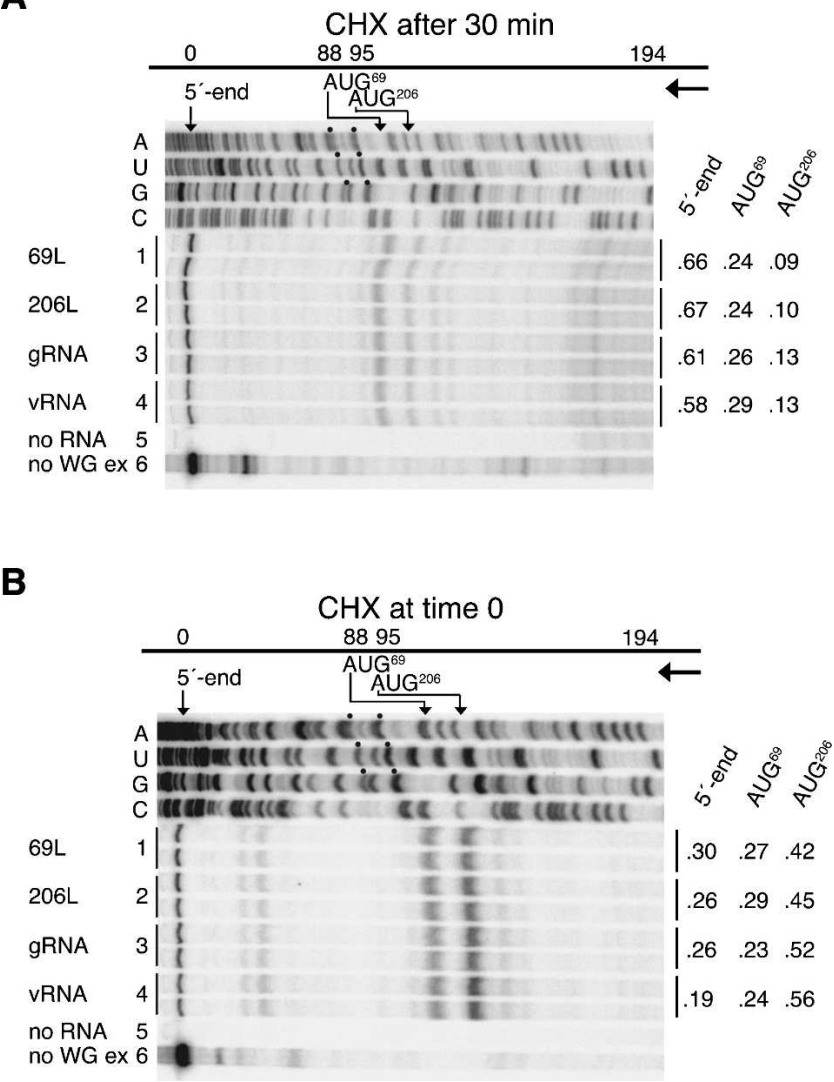

FIGURE 5. Similar ribosome initiation behavior on reporter RNAs and full-length viral RNAs. Toe-printing experiments were conducted in wheat germ extracts in which the RNAs indicated beside each pair of lanes were translated $(A)$ for $30 \mathrm{~min}$ before the addition of cycloheximide $(\mathrm{CHX})$ to block elongation or $(B)$ with cycloheximide present throughout the 30 min incubation. gRNA refers to full-length genomic TYMV in vitro transcript RNA; vRNA refers to virion (genomic) TYMV RNA. The positions of stalled ribosomes are indicated by $5^{\prime}$-end-labeled primer extension products, which have been electrophoresed in 6\% denaturing gels next to marker cDNA products from a sequencing reaction using the same primer and 69L-TYg RNA template (lanes marked A, U, G, C). The positions of $\mathrm{AUG}^{69}$ and $\mathrm{AUG}^{206}$ on the sequence ladders are marked by dots. The major primer extension products correspond to the $5^{\prime}$-end (no ribosome encountered during primer extension) and the $\mathrm{AUG}^{69}$ and $\mathrm{AUG}^{206}$ toe-prints, representing the leading edge of stalled ribosomes ( 16-19 nt downstream of the A of each AUG codon; a similar extended toe-print was reported by Pestova and Hellen 2003). The primer used in the extension reaction primes at nt 194 on TYMV RNA. The three primer extension products are quantified beside each lane. The paired lanes represent duplicate translation and primer extension reactions performed on the same RNA sample. The relative expression of 69L and 206 proteins in this translation extract (not shown) corresponded closely to the ratio of toe-prints in panel $A$. 
Toe-prints accurately reflect the knockout of $\mathrm{AUG}^{69}$ or $\mathrm{AUG}^{206}$ with the loss of the corresponding signal (Fig. 6A, lane 2 ; Fig. $6 \mathrm{~B}$, lanes 2,3 ). The reason for the altered initiation distribution in Figure $5 \mathrm{~B}$ is uncertain but may derive from the fact that the ribosomes assayed in Figure $5 \mathrm{~B}$ were engaged in the initial round of translation, whereas those in Figure 5A were in a steady state of translation. We have observed that reporter RNAs lacking a translation enhancer ( $5^{\prime}$-cap or TYMV $5^{\prime}$ - or $3^{\prime}$-UTR) yield 69L:206L expression ratios as low as 0.44 in cowpea protoplasts (Matsuda et al. 2004). If this reflects differences in mRNA circularization via translation factors and in ribosome recycling (Sachs et al. 1997), these differences might exist between toe-printing experiments where ongoing translation could support such processes (Fig. 5A) and in which the absence of any elongation would not (Fig. 5B).

A

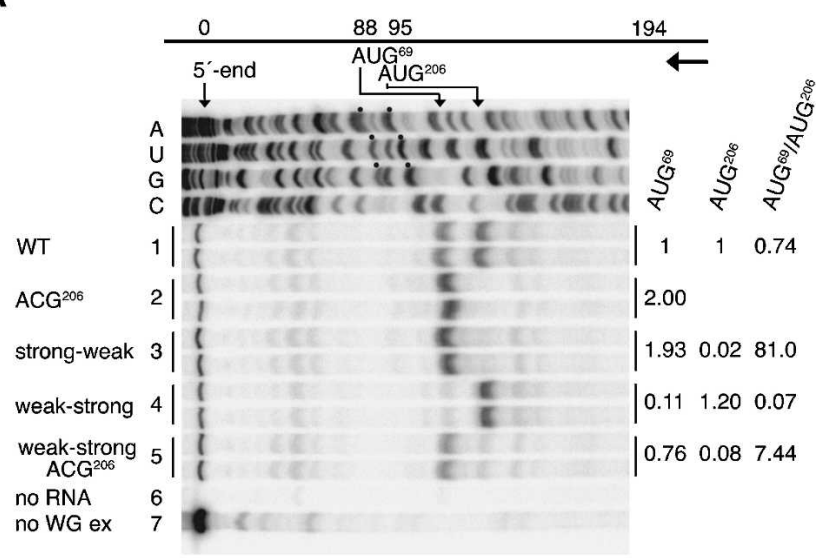

B

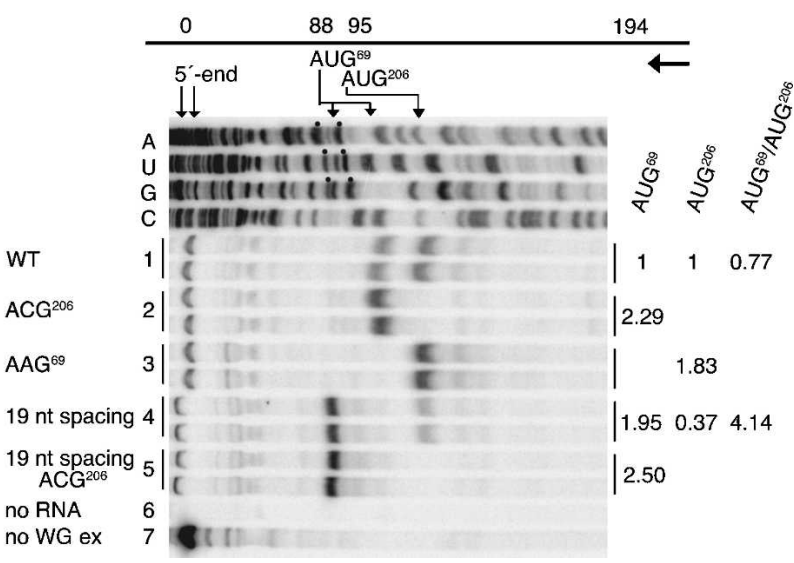

FIGURE 6. Toe-printing reveals correspondence between initiation behavior of ribosomes and protoplast expression data. Toe-print analysis was performed in wheat germ extract in the presence of cycloheximide from time 0 with the indicated variants of 69L-TYg RNA (referred to as WT). (A) Influence of altered initiation contexts and $\mathrm{AUG}^{206}$ knockout on pattern of ribosome initiation. (B) Effect of 19 -nt spacing and $\mathrm{AUG}^{206}$ and $\mathrm{AUG}^{69}$ knockouts. For further details, refer to Figure 5.
Our system is highly responsive to altered initiation contexts, with toe-prints on RNAs with strong-weak and weak-strong context combinations corresponding closely to expression data derived from protoplast experiments (Fig. 6A, lanes 3,4). Most significantly, mutation of $\mathrm{AUG}^{206}$ also altered ribosome initiation patterns in parallel with expression data: Knockout of $\mathrm{AUG}^{206}$ in the wild-type context increased the $\mathrm{AUG}^{69}$ toe-print twofold to 2.3-fold (Fig. 6A,B, cf. lanes 2 and 1), and knockout of $\mathrm{AUG}^{206}$ in the weak-strong context increased the $\mathrm{AUG}^{69}$ toe-print 6.9-fold (0.76/0.11; Fig. 6A, cf. lanes 5 and 4$)$ (the corresponding expression increases of $69 \mathrm{~L}$ in protoplasts were 2.5 -fold and 9.5-fold, respectively; Fig. 4B).

Increasing the spacing between AUGs to $19 \mathrm{nt}$ decreased the number of ribosomes stalled at $\mathrm{AUG}^{206}$ (to 37\%) while increasing the number stalled at $\mathrm{AUG}^{69}$ (to 195\%) (Fig. 6B, lane 4), resulting in predominant initiation from $\mathrm{AUG}^{69}$. Knockout of that downstream-displaced $\mathrm{AUG}^{206}$ caused a much smaller increase in ribosome numbers stalled at $\mathrm{AUG}^{69}$ (Fig. 6B, cf. lanes 5 and 4) compared with knockout of $\mathrm{AUG}^{206}$ in its normal location (Fig. 6A,B, cf. lanes 2 and 1). The correspondence of ribosome initiation behavior with in vivo expression data verifies that the coupling between $\mathrm{AUG}^{69}$ and $\mathrm{AUG}^{206}$ originates from the initiation step.

Using the series of reporter RNAs with increasing spacer lengths, we observed a reciprocal trend of gradually ascending $\mathrm{AUG}^{69}$ recognition (Fig. 7A,B) and descending $\mathrm{AUG}^{206}$ recognition (Fig. $7 \mathrm{~A}, \mathrm{C}$ ). The increase in ribosome stalling at $\mathrm{AUG}^{69}$ in response to $\mathrm{AUG}^{206}$ knockout also diminished with increased spacing, to be almost nonexistent at a spacing of $13 \mathrm{nt}$ and greater (Fig. 7D). These toeprinting results provide strong support that the coupled expression from the two closely positioned AUGs represents an initiation phenomenon.

\section{Coupling between $A U G^{69}$ and $A U^{206}$ does not depend on surrounding TYMV sequences}

The results presented above show that the initiation coupling and resultant enhanced expression from the downstream AUG are not restricted to TYMV context sequences. We further wondered whether these phenomena required specific TYMV flanking sequences or might be more generally applicable to closely spaced AUGs. Initiation coupling, as revealed by the $\mathrm{AUG}^{69}$ expressionenhancing effects of $\mathrm{AUG}^{206}$ knockout and of increased codon spacing, was assessed in RNAs increasingly stripped of TYMV sequences. The effects of $\mathrm{AUG}^{69}$ knockout were studied in parallel. We tested two sets of deletion constructs: a 66-nt deletion removing nt 16 through 81 of the TYMV 5'-UTR, leaving a 21-nt 5'-UTR, and removal of the entire TYMV coding region downstream of the second codon of ORF206 in addition to the $5^{\prime}$-UTR deletion (Fig. $8 \mathrm{~A})$. For both of these constructs, $\mathrm{AUG}^{206}$ knockout and increased spacing to $19 \mathrm{nt}$ resulted in more than twofold 
A

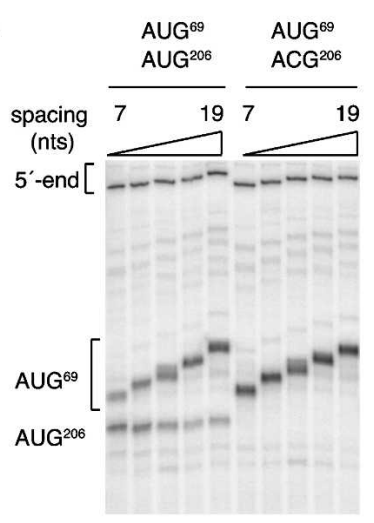

C

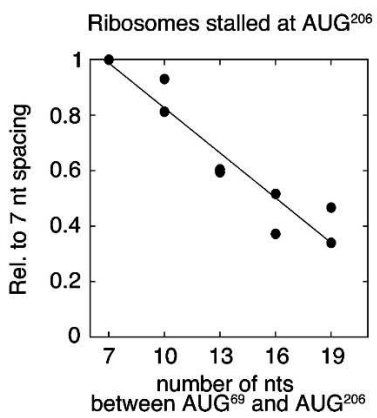

B

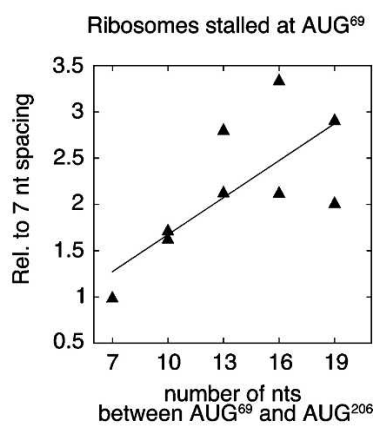

D

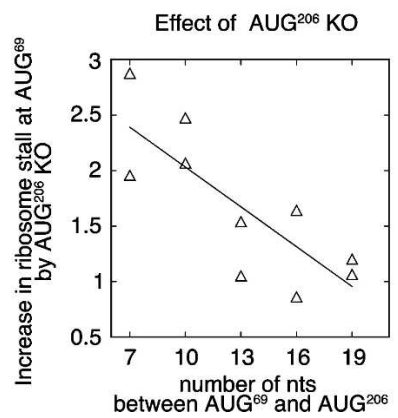

ported expression from $\mathrm{AUG}^{69}$ and $\mathrm{AUG}^{206}$ at a ratio of 4.9 (Fig. 9B). Knockout of $\mathrm{AUG}^{206}$ and an increase in AUG spacing to $19 \mathrm{nt}$ both increased the expression rate from AUG $^{69}$ about twofold (Fig. 9B). The 19-nt spacing also suppressed translation from $\mathrm{AUG}^{206}$ (Fig. 9B), resulting in a monocistronic mRNA with very dominant expression from the upstream $A U G^{69}$. These results suggest that the phenomenon of initiation coupling can be extended to other mRNAs with closely positioned AUGs.

\section{DISCUSSION}

\section{Closely spaced AUG codons are recognized in a modified form of leaky ribosomal scanning that facilitates access to the downstream AUG}

Our experiments on expression from the TYMV AUG ${ }^{69}$ and $\mathrm{AUG}^{206}$ initiation codons, which are $7 \mathrm{nt}$ apart, have revealed aspects of translation that strongly conform to the

A

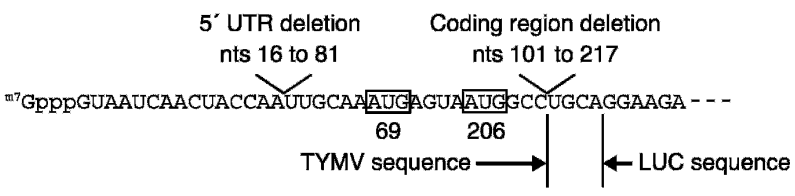

on ribosome initiation profile. (A) Toe-print analysis performed in wheat germ extract as for Figure 6 for variants of 69L-TYg RNA with insertions of increasing length between the two AUGs (see Fig. 2A) and the knockout mutation of $\mathrm{AUG}^{206}$ (right panel). A gel representative of duplicate experiments is shown. Quantification of the results of these duplicate experiments is graphed to indicate $(B)$ the frequency of ribosome initiation at $\mathrm{AUG}^{69},(C)$ the frequency of ribosome initiation at $\mathrm{AUG}^{206}$, and $(D)$ the change in the frequency of ribosome initiation at $\mathrm{AUG}^{69}$ in response to $\mathrm{AUG}^{206}$ knockout.

increase in the translation rate from $\mathrm{AUG}^{69}$ (Fig. 8B,C, column 1). By simultaneously decreasing translation from AUG $^{206}$ (Fig. 8, column 2), the 19-nt separation resulted in higher ratios of 69L to 206L expression (Fig. 8, column 3) and effectively monocistronic mRNAs. These were precisely the observations made with the 69L-TYg and 206L-TYg RNAs. Note that deletion of much of the $5^{\prime}$-UTR results in similar expression levels for 69L and 206L (Fig. 8B, column 3 ), an effect we have reported previously and that is due to the abnormally short $5^{\prime}$-UTR or loss of the translationenhancing effect of the TYMV 5'-UTR (Matsuda et al. 2004). Knockout of $\mathrm{AUG}^{69}$ resulted in the expected increase in expression from $\mathrm{AUG}^{206}$ (Fig. 8, column 2).

In a final test, instead of removing flanking TYMV sequences, we transplanted the short TYMV cassette containing $\mathrm{AUG}^{69}$ and $\mathrm{AUG}^{206}$ (nt 82-100). It was placed between a $5^{\prime}$-UTR comprised of synthetic sequence the same length as the TYMV $5^{\prime}$-UTR and the LUC coding region followed by the polyadenylated $3^{\prime}$-UTR from rabbit $\alpha$-globin mRNA (Fig. 9A). This pair of constructs sup-

B

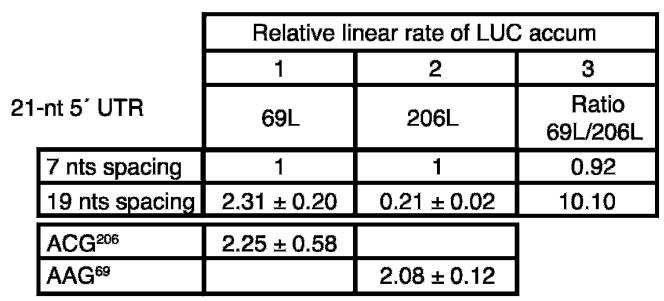

C

\begin{tabular}{|c|c|c|c|}
\hline \multirow{3}{*}{$\begin{array}{c}21 \text { nts } 5 \text {-UTR } \\
\& \\
\triangle \text { TYMV coding region }\end{array}$} & \multicolumn{3}{|c|}{ Relative linear rate of LUC accum } \\
\hline & 1 & 2 & 3 \\
\hline & AUG-69 & AUG-206 & $\begin{array}{r}\text { Ratio } \\
69 / 206\end{array}$ \\
\hline $7 \mathrm{nts}$ spacing & 1 & 1 & 0.71 \\
\hline 19 nts spacing & $2.60 \pm 0.45$ & $0.11 \pm 0.00$ & 16.85 \\
\hline $\mathrm{ACG}^{206}$ & $2.22 \pm 0.36$ & & \\
\hline $\mathrm{AAG}^{69}$ & & $1.57 \pm 0.30$ & \\
\hline
\end{tabular}

FIGURE 8. Initiation coupling of $\mathrm{AUG}^{69}$ and $\mathrm{AUG}^{206}$ persists after deletion of TYMV sequences surrounding the paired initiation codons. (A) Diagram indicating the removal of TYMV sequences from 69L-TYg and 206L-TYg RNAs to produce a 21-nt 5'-UTR and the coding region lacking TYMV sequences. $(B, C)$ Assessment of translational coupling in cowpea protoplasts, as indicated by increased expression of 69L upon knockout of the downstream $\mathrm{AUG}^{206}$ (row "ACG ${ }^{206 ")}$ ) and an increased 69L/206L ratio resulting from increased AUG separation (row "19 nt spacing") (see columns 1 and 3, respectively). 
A

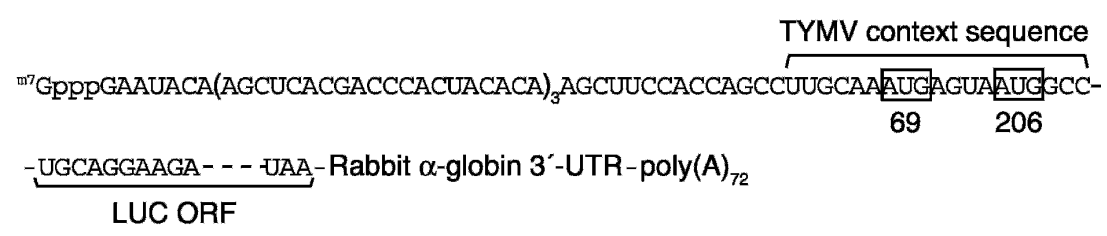

B

\begin{tabular}{|l|c|c|c|}
\cline { 2 - 4 } \multicolumn{1}{c|}{} & \multicolumn{3}{|c|}{ Relative linear rate of LUC accum } \\
\cline { 2 - 4 } \multicolumn{1}{c|}{$\mathrm{L}-\mathrm{p}(\mathrm{A})_{72}$} & AUG-69 & AUG-206 & $\begin{array}{c}\text { Ratio } \\
69 / 206\end{array}$ \\
\hline 7 nts spacing & 1 & 1 & 4.90 \\
\hline 19 nts spacing & $1.95 \pm 0.08$ & $0.07 \pm 0.02$ & 130 \\
\hline AUG-69 (ACG & &
\end{tabular}

FIGURE 9. Initiation coupling of two closely spaced AUGs is independent of surrounding TYMV sequence. (A) Diagram of the $5^{\prime}$-region of LUC reporter RNAs containing the dual $\mathrm{AUG}^{69}$ and $\mathrm{AUG}^{206}$ initiation sites surrounded by an $87 \mathrm{nt}$-long synthetic $5^{\prime}$-UTR (Kozak $1991)$ and a polyadenylated $\left(A_{72}\right)$ rabbit $\alpha$-globin $3^{\prime}$-UTR. $(B)$ LUC expression in cowpea protoplasts from RNAs with $\mathrm{AUG}^{69}$ and $\mathrm{AUG}^{206}$ and from RNAs with an $\mathrm{AUG}^{206}$ knockout mutation and with the two AUG codons separated by $19 \mathrm{nt}$.

normal rules of leaky scanning (Kozak 1999) and others that markedly deviate from these rules. We have employed expression of a LUC reporter gene from RNAs electroporated into plant cells as well as direct observations of initiation site usage by ribosomes in cell-free toe-printing (primer extension inhibition) assays. The strong correspondence observed between these approaches indicates that our LUC expression data reflect ribosome initiation events that are not complicated by different post-initiation ribosome behaviors or other properties between test RNAs. Such differences might arise from differential RNA or protein stability, occlusion of initiation sites by elongating ribosomes (Kozak 1995), or limiting elongation rates in overlapping coding regions (Fajardo and Shatkin 1990). Further, we have observed near-identical ribosome toeprints on LUC reporter RNAs with wild-type viral sequences and on infectious viral RNA (Fig. 5).

We found selection between $\mathrm{AUG}^{69}$ and $\mathrm{AUG}^{206}$ initiation sites to be under the control of the sequence context surrounding each codon (Fig. 4A). Differences in initiation efficiency due to context variation are a fundamental feature of the control of leaky scanning. The conventional view of leaky scanning is that it is strongly $5^{\prime}$-polar, however with decisions at potential initiation sites being made sequentially in a $5^{\prime}-3^{\prime}$ direction. A key observation we report here with respect to the translation of $\mathrm{AUG}^{69}$ and $\mathrm{AUG}^{206}$ is the absence of this strict polarity. This is evidenced by the knockout of the downstream AUG ${ }^{206}$ resulting in twofold to 2.5-fold increased initiation from the upstream $\mathrm{AUG}^{69}$ (Figs. 2B, 6). This response is gradually diminished as the two AUG codons are separated, to the point where it is absent at a spacing of $16-19$ nt (Figs. 2B, 7D). At this spacing, behavior is entirely as expected by leaky scanning.

The observation of a gradual rather than stepwise transition between the two forms of initiation site selection indicates that ribosomes are not responding to some special spacing, but rather that closer proximity increasingly undermines the usually strict $5^{\prime}$ polarity. Selection between close AUGs is a probabilistic and competitive process, the key variables being the context sequences of the two AUGs and their spacing. The competition is best illustrated by the gradual decline in initiation from the upstream $\mathrm{AUG}^{69}$ as $\mathrm{AUG}^{206}$ is moved from a $19-\mathrm{nt}$ to 7 -nt spacing (Figs. 2C, 7B); simultaneously, initiation from $\mathrm{AUG}^{206}$ increases (Figs. 2D, 7C). By elevating expression from the downstream initiation codon, close spacing provides a way to obtain robust dicistronic expression from a given context combination that normally only supports expression from the upstream initiation site. Thus, in their native contexts, separation of the AUG codons from 7 to $19 \mathrm{nt}$ resulted in a change in the ratio of initiation at $\mathrm{AUG}^{69}$ relative to $\mathrm{AUG}^{206}$ from 2.8:1 to 21:1 (Fig. 1D).

Our conclusions differ from those of two previous studies addressing initiation from closely spaced AUG codons but agree with aspects of each. Studying expression of the NB and NA glycoproteins from AUG codons $7 \mathrm{nt}$ apart on influenza B virus RNA segment 6, Williams and Lamb (1989) observed that separation of the initiation codons resulted in an eightfold increase in the NB:NA expression ratio (in favor of the upstream initiation site). At the normal initiation codon spacing, context mutations did not produce responses consistent with contextdependent initiation codon selection, and it was proposed that close apposition of initiation codons allows ribosomes to choose between AUGs on a random basis. A subsequent study that included the NB/NA initiation cassette did detect a responsiveness to changes in the context sequences but rejected the notion that close spacing introduces any modification to normal leaky scanning (Kozak 1995). Although a suppression of downstream initiation was observed when spacing was increased, as reported by Williams and Lamb (1989) and ourselves (Fig. 2), this was concluded to be due to post-initiation elongation events (Kozak 1995). We offer the alternative interpretation that the toe-printing data of Figure 4 in Kozak (1995) actually presents the same phenomenon we describe here. That is, the relative downstream initiation when AUG codons are close [construct K46(5)] is much greater than when they are distant (construct $\mathrm{K}_{0} 46$ ), 
and conversely the relative upstream initiation is greater when AUG codons are distant than when they are close.

\section{Both extensively overlapping ORFs in TYMV RNA are translated by modified leaky scanning}

It was postulated recently that translation from $\mathrm{AUG}^{206}$ of TYMV RNA occurs via a unique cap-independent mechanism that depends on the $3^{\prime}$-tRNA-like structure (the socalled Trojan horse model; Barends et al. 2003). We have previously shown with LUC reporter RNAs that expression from both $\mathrm{AUG}^{69}$ and $\mathrm{AUG}^{206}$ is strongly cap-dependent in plant cells (Matsuda et al. 2004), and we show here that ribosomes reach both AUG codons after association with the $5^{\prime}$-end of the RNA (Fig. 3). All of our results can be explained by conventional ribosome delivery to the initiation AUGs.

Our expression studies with these nested AUGs have been performed with LUC reporter RNAs that have considerable $5^{\prime}$ - and $3^{\prime}$-TYMV sequence but that are much shorter than genomic TYMV RNA. It has been argued that authentic viral and the LUC reporter RNAs may be translated in distinct ways, and that the cap-independent "Trojan horse" mode of initiation is not observable with the LUC RNAs (Rudinger-Thirion et al. 2005). This contention is not supported by our toe-printing results, which show the same ribosome initiation behavior on the LUC reporter and viral genomic RNAs (Fig. 5A,B).

\section{Closely positioned AUG codons as a general signal for potential dicistronic expression}

By varying the initiation site context sequences (Fig. 4) and deleting or replacing other TYMV sequences (Figs. 8, 9), we have shown that the special expression behavior associated with closely spaced initiation codons does not appear to be dependent on TYMV sequences. The modified form of leaky scanning that favors access to the downstream AUG should thus be accessible to all mRNAs in which the two $5^{\prime}$-most AUG triplets are closely spaced. This is probably the expression mode for all tymoviral RNAs, whose $5^{\prime}$-most AUGs have the conserved 7-nt spacing but variable sequence contexts.

This expression mode should be generally available for plant mRNAs, resulting in facilitated expression from a downstream initiation site that is normally more strongly blocked by the limited leakiness of an upstream AUG. Given the conserved nature of the translation apparatus among higher eukaryotes, this strategy for dicistronic expression could be generally applicable for higher eukaryotic mRNAs. It is possible that, without considering the effects of closely spaced AUG codons, the expression of numerous peptides from eukaryotic genomes will be overlooked.

\section{A model for $5^{\prime}-3^{\prime}$ ribosome scanning occurring as the net effect of forward and backward oscillations}

The precise way in which eukaryotic ribosomes scan through the $5^{\prime}$-UTR is not understood, but the possibility that this includes some reverse motion has been considered (Berthelot et al. 2004; Kapp and Lorsch 2004; Jackson 2005). We propose that the best explanation for the coupled, competitive expression from closely spaced initiation codons such as $\mathrm{AUG}^{69}$ and $\mathrm{AUG}^{206}$ is that scanning occurs with some bidirectional oscillations. The experiments of Figures 2 and 7 allow an estimate of the amplitude of this oscillation. The increased 69L expression resulting from $\mathrm{AUG}^{206}$ knockout is a measure of coupling between closely spaced AUGs, representing the lost upstream initiations when ribosomes have been trapped by initiation at the downstream AUG. The coupling effect is no longer observable at a spacing of 16-19 nt (Figs. 2B, 7D), suggesting that ribosomes move with backward excursions somewhat less than this spacing, i.e., about $15 \mathrm{nt}$, during scanning. Initiation cassettes with closely spaced AUG codons may provide a useful means for a closer study of ribosome scanning, particularly with single-molecule studies.

\section{MATERIALS AND METHODS}

\section{DNA constructs and in vitro transcription}

All variants of the TYMV 5'-sequence were generated with PCR using mutagenic primers. After digestion with Not $\mathrm{I}$ and Pst I, the fragments containing the T7 promoter and 5'-TYMV sequences were inserted in front of the firefly luciferase (LUC) coding region in pDCL-TYg (Matsuda et al. 2004) or pGCLGpA (Chiu et al. 2005), which contain the $3^{\prime}$-UTR sequence from TYMV genomic RNA or rabbit $\alpha$-globin mRNA with an $A_{72}$ tract, respectively. This created p69L-TYg and p206L-TYg (Fig. 1C) and derivatives. All constructs were verified by DNA sequencing. Prior to in vitro transcription, the plasmids with either $3^{\prime}$-TYMV sequence were linearized by cleavage with $X m n I$, and those with a poly $(A)_{72}$ tract with Acc65I. Full-length TYMV RNA was transcribed from pTYMC (Weiland and Dreher 1989) linearized with HindIII. Capped RNA transcripts were made with T7 RNA polymerase and inspected by electrophoresis as described (Matsuda et al. 2004).

\section{Protoplast transfection}

Capped RNA transcripts $(2 \mathrm{pmol})$ were introduced into $0.45 \times$ $10^{6}$ cowpea mesophyll protoplasts via electroporation as described (Matsuda et al. 2004). The protoplasts were harvested at eight time points up to $6 \mathrm{~h}$ post-transfection and lysed with Passive Lysis Buffer (Promega). LUC activity was measured with a 1450 Microbeta Trilux counter (Wallac) (Matsuda et al. 2004). Results were normalized to total protein amounts as determined in a Coomassie dye-binding assay (BioRad). For a particular RNA construct, two independently prepared transcripts were studied in duplicate to determine the linear rate of LUC production (relative light units / $\mathrm{mg}$ protein / hour) as a measure of translation efficiency. 


\section{Primer extension-inhibition (toe-print) analysis to detect bound ribosomes}

Wheat germ extract was prepared according to Morch et al. (1986) except for omission of the organic solvent flotation step. Assay conditions were adapted from Ryabova and Hohn (2000). In vitro transcribed RNA (50 fmol in $10 \mu \mathrm{L}$ reaction) was mixed with $3 \mu \mathrm{L}$ of wheat germ extract and incubated at $26^{\circ} \mathrm{C}$ for $30 \mathrm{~min}$ in $20 \mathrm{mM}$ HEPES ( $\mathrm{pH} 7.6$ ), $75 \mathrm{mM}$ potassium acetate, $1.7 \mathrm{mM}$ magnesium acetate, $1.2 \mathrm{mM}$ ATP, $0.3 \mathrm{mM}$ GTP, $10 \mathrm{mM}$ creatine phosphate, $50 \mu \mathrm{g} / \mu \mathrm{L}$ creatine phosphokinase, $2 \mathrm{mM}$ DTT, $0.6 \mathrm{mM}$ spermidine, $0.8 \mathrm{U} / \mu \mathrm{L}$ RNase OUT ribonuclease inhibitor (Invitrogen), and $50 \mathrm{nM}$ each amino acid. Cycloheximide $(0.9 \mathrm{mM})$ was added at the appropriate time.

Primer extension to detect toe-prints was performed as described (Sachs et al. 2002). The oligomer 5'-CATGGGTAGGTCT GTATCGA-3', which primes at nt 194 of TYMV RNA, was $5^{\prime}$-end-labeled with $\left[\gamma^{-}{ }^{32} \mathrm{P}\right]$ ATP $(>6000 \mathrm{Ci} / \mathrm{mmol}$, PerkinElmer) and purified with a QIAquick nucleotide removal kit (Qiagen). Three microliters of the translation reaction were transferred to $5 \mu \mathrm{L}$ annealing buffer ( $50 \mathrm{mM}$ Tris-acetate [pH 7.5], $75 \mathrm{mM}$ potassium acetate, $5 \mathrm{mM}$ magnesium acetate, $0.25 \mathrm{mM}$ each dNTP, $10 \mathrm{mM}$ DTT, $1 \mathrm{U} / \mu \mathrm{L}$ RNase OUT, $0.5 \mathrm{mM}$ cycloheximide). The mixture was incubated at $55^{\circ} \mathrm{C}$ for $2 \mathrm{~min}$ and then placed on ice. The $5^{\prime}$-labeled primer $(1 \mu \mathrm{L}, 0.1 \mathrm{pmol})$ was added and annealed to the RNA at $37^{\circ} \mathrm{C}$ for $5 \mathrm{~min}$. Superscript II reverse transcriptase (Invitrogen) $(1 \mu \mathrm{L}, 50 \mathrm{U})$ was added to allow primer extension at $37^{\circ} \mathrm{C}$ for $30 \mathrm{~min}$. Samples were analyzed by $6 \%$ denaturing polyacrylamide gel electrophoresis and phosphorimagery (Molecular Dynamics).

\section{ACKNOWLEDGMENTS}

We thank Matthew Sachs and Anthony Gaba for instruction and advice in the toe-printing procedure, and Matthew Sachs and members of the Dreher laboratory for critical reading of the manuscript. We appreciate assistance by Wei-Wei Chiu in some experiments. This work was supported by NSF grant MCB0235563.

Received February 18, 2006; accepted March 30, 2006.

\section{REFERENCES}

Bab, I., Smith, E., Gavish, H., Attar-Namdar, M., Chorev, M., Chen, Y.C., Muhlrad, A., Birnbaum, M.J., Stein, G., and Frenkel, B. 1999. Biosynthesis of osteogenic growth peptide via alternative translational initiation at AUG85 of histone H4 mRNA. J. Biol. Chem. 274: 14474-14481.

Barends, S., Bink, H.H., van den Worm, S.H., Pleij, C.W., and Kraal, B. 2003. Entrapping ribosomes for viral translation: tRNA mimicry as a molecular Trojan horse. Cell 112: 123-129.

Berthelot, K., Muldoon, M., Rajkowitsch, L., Hughes, J., and McCarthy, J.E. 2004. Dynamics and processivity of 40S ribosome scanning on mRNA in yeast. Mol. Microbiol. 51: 987-1001.

Chiu, W.W., Kinney, R.M., and Dreher, T.W. 2005. Control of translation by the $5^{\prime}$ - and $3^{\prime}$-terminal regions of the dengue virus genome. J. Virol. 79: 8303-8315.

Churbanov, A., Rogozin, I.B., Babenko, V.N., Ali, H., and Koonin, E.V. 2005. Evolutionary conservation suggests a regulatory function of AUG triplets in $5^{\prime}$-UTRs of eukaryotic genes. Nucleic Acids Res. 33: 5512-5520.

Dreher, T.W. 2004. Pathogen profile. Turnip yellow mosaic virus: Transfer RNA mimicry, chloroplasts and a C-rich genome. Mol. Plant Pathol. 5: 367-375.

Fajardo, J.E. and Shatkin, A.J. 1990. Translation of bicistronic viral mRNA in transfected cells: Regulation at the level of elongation. Proc. Natl. Acad. Sci. 87: 328-332.

Hinnebusch, A.G. 2005. Translational regulation of GCN4 and the general amino acid control of yeast. Annu. Rev. Microbiol. 59: 407-450.

Iacono, M., Mignone, F., and Pesole, G. 2005. uAUG and uORFs in human and rodent 5'untranslated mRNAs. Gene 349: 97-105.

Jackson, R.J. 2005. Alternative mechanisms of initiating translation of mammalian mRNAs. Biochem. Soc. Trans. 33: 1231-1241.

Jan, E. 2005a. Divergent IRES elements in invertebrates. Virus Res. [Epub, doi:10.1016/j.virusres. 2005.10.011].

Joshi, C.P., Zhou, H., Huang, X., and Chiang, V.L. 1997. Context sequences of translation initiation codon in plants. Plant Mol. Biol. 35: 993-1001.

Kapp, L.D. and Lorsch, J.R. 2004. The molecular mechanics of eukaryotic translation. Annu. Rev. Biochem. 73: 657-704.

Kawaguchi, R. and Bailey-Serres, J. 2005. mRNA sequence features that contribute to translational regulation in Arabidopsis. Nucleic Acids Res. 33: 955-965.

Kozak, M. 1989. Circumstances and mechanisms of inhibition of translation by secondary structure in eucaryotic mRNAs. Mol. Cell. Biol. 9: 5134-5142.

. 1991. Effects of long $5^{\prime}$ leader sequences on initiation by eukaryotic ribosomes in vitro. Gene Expr. 1: 117-125.

. 1995. Adherence to the first-AUG rule when a second AUG codon follows closely upon the first. Proc. Natl. Acad. Sci. 92: 2662-2666.

- 1999. Initiation of translation in prokaryotes and eukaryotes. Gene 234: 187-208.

. 2002. Pushing the limits of the scanning mechanism for initiation of translation. Gene 299: 1-34.

Lukaszewicz, M., Feuermann, M., Jerouville, B., Stas, A., and Boutry, M. 2000. In vivo evaluation of the context sequence of the translation initiation codon in plants. Plant Sci. 154: 89-98.

Matsuda, D., Bauer, L., Tinnesand, K., and Dreher, T.W. 2004. Expression of the two nested overlapping reading frames of turnip yellow mosaic virus RNA is enhanced by a $5^{\prime}$ cap and by $5^{\prime}$ and 3' viral sequences. J. Virol. 78: 9325-9335.

Morch, M.D., Drugeon, G., Zagorski, W., and Haenni, A.L. 1986. The synthesis of high-molecular-weight proteins in the wheat germ translation system. Methods Enzymol. 118: 154-164.

Niepel, M. and Gallie, D.R. 1999. Identification and characterization of the functional elements within the tobacco etch virus $5^{\prime}$ leader required for cap-independent translation. J. Virol. 73: 90809088.

Oyama, M., Itagaki, C., Hata, H., Suzuki, Y., Izumi, T., Natsume, T., Isobe, T., and Sugano, S. 2004. Analysis of small human proteins reveals the translation of upstream open reading frames of mRNAs. Genome Res. 14: 2048-2052.

Pestova, T.P. and Hellen, C.U.T. 2003. Translation elongation after assembly of ribosomes on the Cricket paralysis virus internal ribosome entry site without initiation factors or initiator tRNA. Genes \& Dev. 17: 181-186.

Pestova, T.V., Kolupaeva, V.G., Lomakin, I.B., Pilipenko, E.V., Shatsky, I.N., Agol, V.I., and Hellen, C.U. 2001. Molecular mechanisms of translation initiation in eukaryotes. Proc. Natl. Acad. Sci. 98: 7029-7036.

Rudinger-Thirion, J., Olsthoorn, R.C.L., Giegé, R., and Barends, S. 2005. Idiosynchratic behaviour of tRNA-like structures in translation of plant viral RNA genomes. J. Mol. Biol. 355: 873-878.

Ryabova, L.A. and Hohn, T. 2000. Ribosome shunting in the cauliflower mosaic virus $35 \mathrm{~S}$ RNA leader is a special case of 
reinitiation of translation functioning in plant and animal systems. Genes \& Dev. 14: 817-829.

Sachs, A.B., Sarnow, P., and Hentze, M.W. 1997. Starting at the beginning, middle, and end: Translation initiation in eukaryotes. Cell 89: 831-838.

Sachs, M.S., Wang, Z., Gaba, A., Fang, P., Belk, J., Ganesan, R., Amrani, N., and Jacobson, A. 2002. Toeprint analysis of the positioning of translation apparatus components at initiation and termination codons of fungal mRNAs. Methods 26: 105-114.

Smith, E., Meyerrose, T.E., Kohler, T., Namdar-Attar, M., Bab, N., Lahat, O., Noh, T., Li, J., Karaman, M.W., Hacia, J.G., et al. 2005. Leaky ribosomal scanning in mammalian genomes: Significance of histone $\mathrm{H} 4$ alternative translation in vivo. Nucleic Acids Res. 33: 1298-1308.

Weiland, J.J. and Dreher, T.W. 1989. Infectious TYMV RNA from cloned cDNA: Effects in vitro and in vivo of point substitutions in the initiation codons of two extensively overlapping ORFs. Nucleic Acids Res. 17: 4675-4687.

Williams, M.A. and Lamb, R.A. 1989. Effect of mutations and deletions in a bicistronic mRNA on the synthesis of influenza $B$ virus NB and NA glycoproteins. J. Virol. 63: 28-35.

Yamashita, R., Suzuki, Y., Nakai, K., and Sugano, S. 2003. Small open reading frames in $5^{\prime}$ untranslated regions of mRNAs. C.R. Biol. 326: 987-991. 

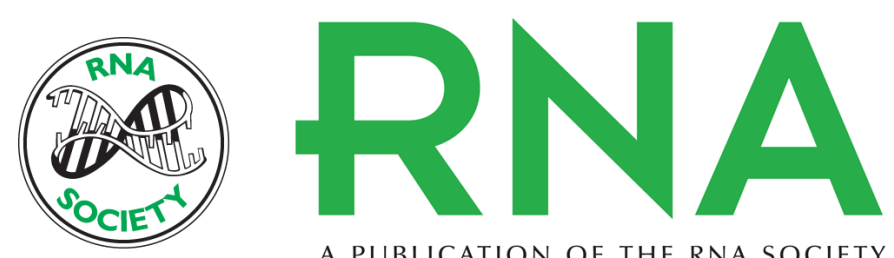

A PUBLICATION OF THE RNA SOCIETY

\section{Close spacing of AUG initiation codons confers dicistronic character on a eukaryotic mRNA}

Daiki Matsuda and Theo W. Dreher

RNA 2006 12: 1338-1349

References This article cites 33 articles, 12 of which can be accessed free at:

http://rnajournal.cshlp.org/content/12/7/1338.full.html\#ref-list-1

License

Email Alerting Receive free email alerts when new articles cite this article - sign up in the box at the Service top right corner of the article or click here.

To subscribe to RNA go to:

http://rnajournal.cshlp.org/subscriptions 